\title{
ANÁLISE DO ENDOMARKETING DE UMA EMPRESA DO RAMO DE AVIAMENTOS DE CRICIÚMA - SC
}

DOI: http://dx.doi.org/10.18616/pers06

Bruna Brigido Escaravaco - Unesc

E-mail: bruna_brigido@hotmail.com José Carlos Virtuoso - Unesc

E-mail: jcv@unesc.net 


\section{INTRODUÇÃO}

Com o passar dos anos, os processos tecnológicos e culturais têm sofrido transformações significativas, sobretudo no âmbito organizacional, marcadamente com grandes avanços, não sendo diferente na área do marketing. Nesse contexto, surgiu a necessidade de o marketing avançar também, ganhando distintos significados e criando diferentes tarefas, dentro de um processo de adequação ao novo cenário (KOTLER, 1981). O endomarketing surge a partir dessas mudanças, sendo uma grande estratégia para a competição de mercado, que compreende o marketing interno da empresa, sendo necessário "vender" o produto ou serviço primeiramente para o funcionário.

O objetivo do endomarketing é criar fidelidade entre o público interno, compartilhando ideias e objetivos para empresa, cultivando sempre o objetivo de melhorar o relacionamento entre os colaboradores e os gestores da organização. Este capítulo apresenta a experiência da aplicação do endomarketing dentro de uma empresa do ramo de aviamentos, a qual se localiza em Criciúma, Santa Catarina, cujas vendas se direcionam a grandes confecções da região. Buscou-se, por meio da abordagem qualitativa, levantar indicadores sobre as ações de endomarketing. Desse modo, deverão ser apresentadas algumas contribuições para a melhoria do processo em questão.

Considerando o plano de expansão em curso da empresa pesquisada com a compra de equipamentos para aumentar sua gama de produtos, torna-se oportuna a criação de um programa de endomarketing como política organizacional, sobretudo porque a empresa não conta com um setor de $\mathrm{RH}$, sendo o relacionamento interno diretamente vivenciado entre os funcionários e o gestor, o que pode ocasionar barreiras na comunicação por causa de um possível constrangimento do público interno.

\section{DO MARKETING AO ENDOMARKETING}

Antes de se abordar o conceito de endomarketing, é oportuno compreender a sua origem, que é o marketing. Este pode ser utilizado por qualquer profissional, seja ele médico ou vendedor de cachorro-quente, advogado ou jogador de futebol. Cada um desses profissionais precisa entender e criar aquilo que seu público-alvo necessita. Por meio de estudos, criatividade e ofertas, estar sempre à 
disposição para atender às necessidades de seu cliente final. Assim, cada empresa tem sua identidade, podendo usar o marketing para prospectar aonde quer chegar e definir quem vai atender.

O Marketing tem em sua estrutura quatro compostos que definem qualquer uma de suas estratégias, ou seja, os quatro Ps: Preço, Praça, Produto e Promoção. De acordo com Urdan e Urdan (2006), o Preço é o valor cobrado para determinado produto ou serviço, porém precisa ser compatível com os benefícios que o cliente vai receber por meio da compra. Praça é o local onde o produto será oferecido para a venda. O produto precisa estar no local no momento em que o cliente for procurá-lo. Da mesma forma, a praça pode ser considerada um conjunto de organizações com o devido fim de transportar, armazenar e distribuir o produto esperado pelo cliente. O Produto é a mercadoria, que tem como objetivo satisfazer os desejos ou as necessidades do consumidor. Cada produto, por meio de suas qualidades, traz benefícios e valor para o consumidor final. A Promoção é feita por meio de informações que a empresa vai apresentar ao seu consumidor final; sendo assim, é a estratégia adotada para a divulgação do produto. Por meio da promoção, os clientes ficam sabendo do valor e da valorização do produto dentro do mercado.

Quando se fala em marketing, a maioria das pessoas supõe que essa palavra se resume a vendas e a propagandas. O que é compreensível, até certo ponto, pois estamos sempre rodeados de todos os tipos de propagandas. Mas, com o passar dos anos, o marketing transformou-se em algo muito maior, indo muito além de uma simples propaganda ou venda. Portanto, satisfazer a necessidade do cliente é objetivo principal do marketing (KOTLER; ARMSTRONG, 2000).

Para que a satisfação do cliente aconteça, é necessário um bom profissional de marketing, o qual precisa entender essas necessidades da área, cumprindo seu papel de acordo com as exigências do mercado, facilitando também a compra do cliente. Em um simples resumo, conforme Kotler e Armstrong (2000), marketing é um conjunto de ferramentas que, juntas, trabalham para causar efeito no mercado, o qual não deve ser "[...] compreendido apenas como no antigo sentindo de fazer uma venda - 'dizer e vender' -, mas também no novo sentido de satisfazer a necessidade do cliente." (KOTLER; ARMSTRONG, 2000, p. 3).

Se o marketing representa um importante instrumento para a construção e a consolidação dos negócios voltados ao público externo, tem-se o endomarketing como ferramenta para cuidar da parte interna, estabelecendo lealdade entre a empresa e o seu público interno. Com o alcance dessa relação de reciprocidade, 
acaba-se chegando ao objetivo do endomarketing, com a geração de vínculos mais profundos entre funcionários e organização, sendo o resultado final revertido em melhorias para a empresa (BEKIN, 2005), conceito que será aprofundado na sequência.

\section{O ENDOMARKETING}

Cada empresa tem sua realidade, sua cultura administrativa e seu jeito de administrar sua cultura interna. No entanto, o método de cuidado do ambiente interno da empresa pode estar bem definido ou nem tanto. Às vezes, o que era para estar ajudando, pode estar atrapalhando a empresa de alguma forma (BRUM, 2005). Considerando esse contexto, o endomarketing vem para ajudar, como uma alternativa para o comprometimento do público interno dentro da empresa, contexto no qual o funcionário continua sendo um subordinado, mas que deve ser tratado como cliente (INKOTTE, 2000).

Quando o endomarketing começou a ser tratado como estratégia de motivação voltada ao público interno da organização, foi visto como uma barreira que dividia funcionário e cliente. Isso porque, com o tratamento do público interno como seu principal cliente, o cliente externo poderia pensar que se tornaria parte secundária da organização. Desse modo, para que isso não acontecesse, tomou-se como medida explicar ao funcionário sobre a sua importância e sobre a importância do cliente. Com a motivação dos funcionários, há possibilidade de haver um melhor atendimento ao cliente, o que contribui para o crescimento da empresa (BEKIN, 2005).

O Endomarketing, portanto, vem para ajudar a "educar" os funcionários da organização. Brum (2005, p. 57) explica que ele é um processo educativo e que, "[...] se o produto da comunicação interna é a informação e se o treinamento é a forma de se transmitir informação e conhecimento, podemos dizer que o treinamento é um dos mais importantes instrumentos de endomarketing". Isso é muito observado nas reuniões dentro das organizações, nas quais são colocados à disposição do público interno alguns programas que servem para motivá-los e orientá- los para cada vez mais alcançarem o objetivo da empresa. Com algumas técnicas, a empresa pode acabar afastando algumas dificuldades de aprendizagem, criando um ambiente renovado e com funcionários educados. "Educação, portanto, é um dos principais fatores a serem levados em consideração quando se está planejando um programa de endomarketing." (BRUM, 2005, p. 59). 
A exemplo do marketing, que é composto por quatro Ps, atendendo às necessidades do consumidor, o endomarketing também apresenta tais componentes, só que destinados ao cliente interno, cuidando, assim, da motivação dos funcionários. Nesse contexto, formam o composto de endomarketing os quatro Cs, que são: Companhia, Custos, Coordenadores e Comunicação.

Figura 1 - Significado dos quatro Cs do endomarketing

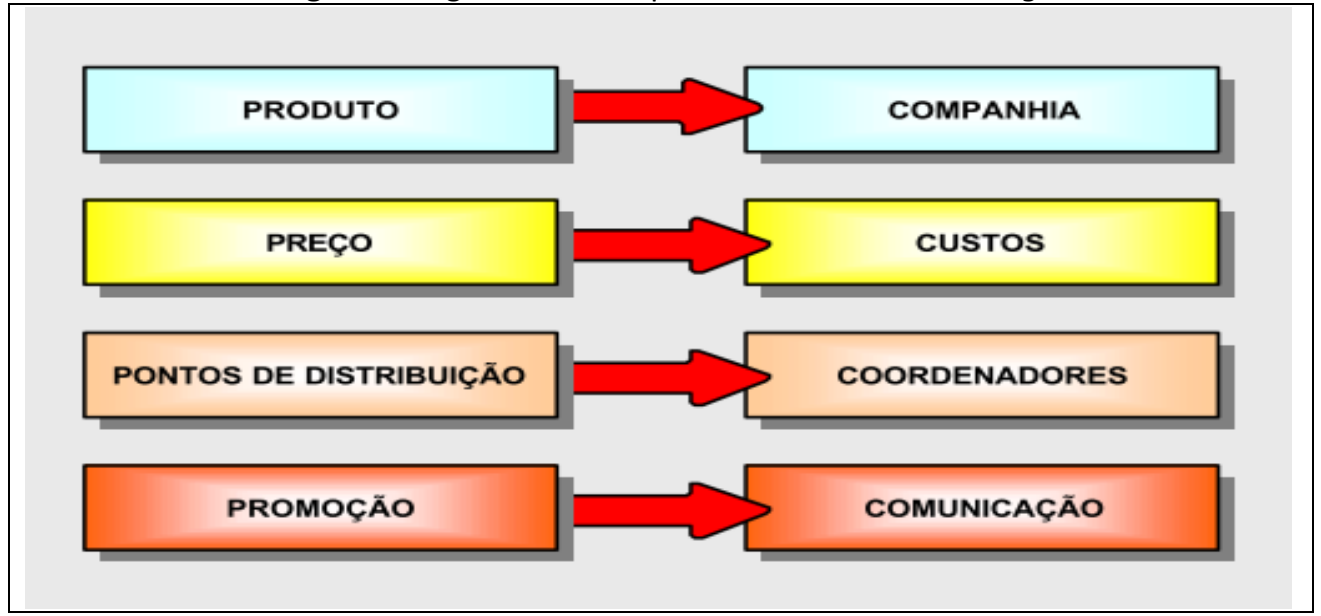

Fonte: Inkotte (2000).

Companhia: sofre mudanças contínuas para promover motivação, fazendo o público interno sentir-se bem no ambiente de trabalho. A partir desse composto, começa a surgir um diferencial competitivo.

Custos: investimentos em programas e matérias de endomarketing para aperfeiçoar e capacitar o público interno.

Coordenadores: são responsáveis por comandar os programas implantados na empresa. Podem ser líderes, gerentes ou voluntários, desde que saibam comandar um programa de endomarketing.

Comunicação: coleta de informações para ferramentas do endomarketing (INKOTTE, 2000).

\section{A importância do endomarketing na empresa}

Dentre os motivos para a empresa adotar o plano de endomarketing está o fortalecimento das relações internas, que trazem melhorias aos produtos ou 
serviços produzidos e vendidos, ao atendimento aos clientes e também à produtividade pessoal. Quanto melhor for o plano de marketing, mais atraente será a empresa como local de trabalho.

Minadeo (2008) aponta que o endomarketing e o marketing interno consistem em tratar o funcionário como cliente. Um funcionário bem satisfeito com o seu trabalho, e bem informado, é o melhor agente de marketing que a empresa pode ter. Para estar fortalecendo cada vez mais essa relação funcionário-empresa, é necessário que sejam estabelecidas rotinas, com intuito de ouvir os funcionários e apresentar a eles quais são os objetivos da empresa. Toda mudança de rotina nos serviços deve ser comunicada aos funcionários. O que não pode acontecer são as "fofocas" e a tentativa de adivinhar algo sobre a empresa e/ou sobre o seu futuro. "O endomarketing é eficiente para manter a equipe motivada, mas, além disso, há outras questões que devem ser consideradas", reforça Minadeo (2008, p. 224).

Em se tratando do desenvolvimento de um programa de endomarketing, a escolha das pessoas que irão promover os treinamentos é fundamental. A equipe de treinamento precisa buscar também a integração do grupo e a diminuição das rivalidades dentro da empresa. Por fim, é fundamental ressaltar que todos os envolvidos na prestação de serviços devem fazer parte desse processo e precisam participar de todo o programa (MINADEO, 2008).

\section{Motivação no ambiente de trabalho}

Cada pessoa tem um jeito de ser, um comportamento diferente, ou seja, há variedades nos comportamentos humanos. Apesar dessas variedades, todos os funcionários gostam de receber elogios, de serem agradados e valorizados. A motivação dentro da empresa é necessária para que o funcionário se sinta lembrado e desempenhe seu trabalho com qualidade (BERGAMINI, 1997).

A motivação no ambiente de trabalho é favorecida ou não de acordo com o ambiente da empresa. Se ela adota uma política de submeter seus funcionários, provavelmente eles não estarão motivados a exercerem a função corretamente. Mas, por outro lado, se estiverem trabalhando em um local onde têm liberdade para se posicionar, para dar sua opinião, além de trabalharem em um ambiente mais "leve", já estarão sendo motivados. Para isso acontecer, é preciso que os gestores reconheçam a realidade de seus subordinados e que entendam os problemas pelos quais estes passam durante o tempo em que estão na empresa (LOEN, 1976). 
Motivação nada mais é que uma recompensa que o público interno ganha ao desempenhar seu trabalho. Muitas vezes, essa recompensa pode se dar por meio de elogios, de gestos que fazem o funcionário se sentir útil na empresa e até mesmo por meio de premiações mensais. Essa motivação pode vir do ambiente, por exemplo, por meio dos móveis, da água, da segurança, e também por meio de afeto, proteção, companheirismo e elogios (LOEN, 1976).

A motivação de um ser humano está associada diretamente ao atendimento de suas necessidades em vários aspectos. Dentro dessa perspectiva, a Pirâmide de Maslow apresenta a hierarquia das necessidades, em uma representação do que uma pessoa precisa para alcançar o crescimento e a satisfação. As necessidades começam a ser alcançadas pelo nível mais baixo; depois se vai alcançando as de nível mais alto até se chegar ao topo. Iniciam pelas necessidades fisiológicas, seguidas pela segurança, pelo amor/relacionamento e pela estima, até chegarem à realização pessoal. Quando o ser humano chega à realização pessoal, ele conseguiu suprir suas metas. Para isso acontecer, precisa de uma boa alimentação, de amizades, da família, de segurança quanto aos seus recursos, de autoestima, de confiança, de moralidade, de criatividade, dentre outros aspectos (MASLOW, 2001).

Figura 2 - Pirâmide de Maslow

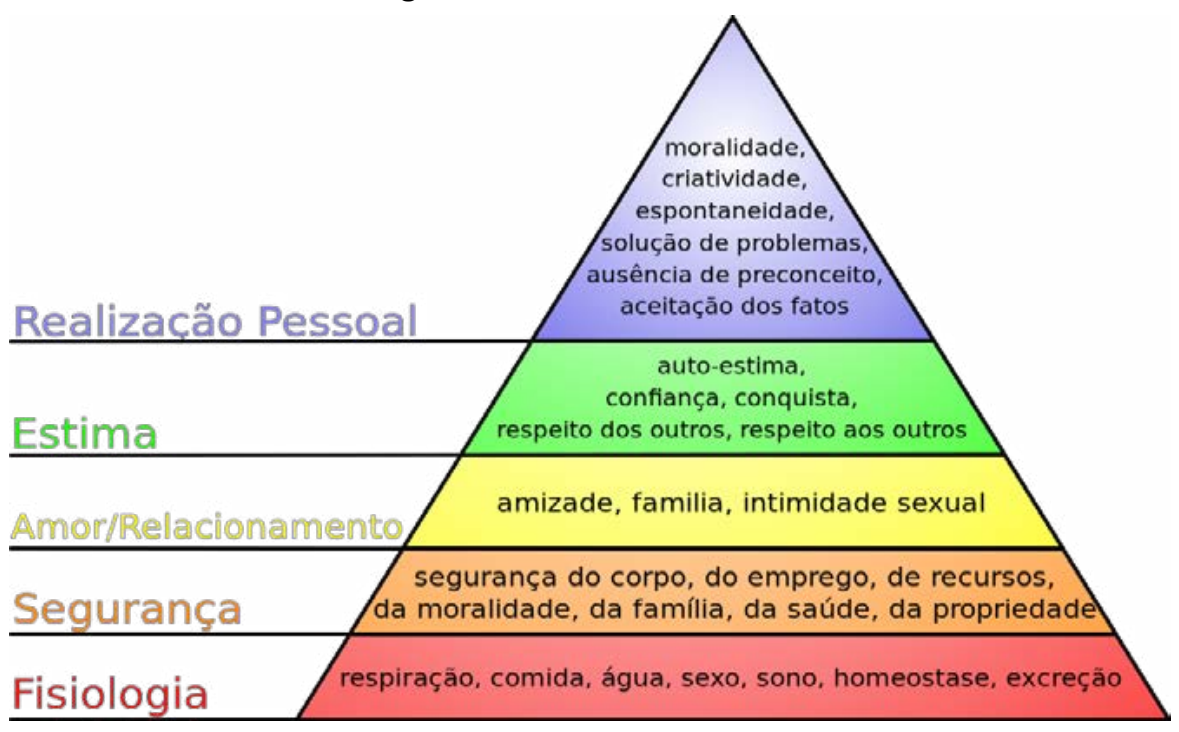

Fonte: Allen (2016). 
Portanto, considerando a valorosa contribuição de Maslow com a hierarquia das necessidades, qualquer proposta relacionada ao endomarketing deve, necessariamente, levar em conta esses elementos, a fim de que as ações possam ter o resultado almejado. Os resultados finais de um programa de endomarketing começam a apresentar êxito exatamente quando a empresa consegue conquistar seus primeiros clientes, os seus funcionários.

\section{Resultados finais do endomarketing}

Com os projetos de endomarketing finalizados, a empresa não deverá ganhar apenas no âmbito interno, como também no externo, tendo em vista que seus produtos ou serviços provavelmente serão bem vistos pelos clientes. $O$ endomarketing facilita as vendas, mas também contribui para o relacionamento interno da empresa (MINADEO, 2008). Bekin (2005, p. 24) afirma que o objetivo final do marketing é "[...] criar um produto ou serviço cuja qualidade corresponda às necessidades, aos desejos e às expectativas do consumidor". Já o endomarketing é uma motivação para o melhor atendimento ao cliente e para a satisfação do funcionário.

Minadeo (2008, p. 226) destaca que o "Programa de endomarketing visa conscientizar os Recursos Humanos da importância da prestação de serviço de elevada qualidade ao consumidor", ou seja, que as pessoas sigam os princípios e trabalhem com mais dedicação.

Cerqueira (1999, p.133) levanta alguns pontos que estão ligados ao objetivo do endomarketing:

\footnotetext{
Melhora a qualidade do trabalho, segurança, limpeza, ordem, entre outros quesitos; avaliações para identificação de quais áreas e setores precisam de assistência técnica e operacional; promoção, entre toda a empresa, de um espírito de união para que realizem bem o trabalho, aceitando novos desafios e vivendo em harmonia.
}

Por sua vez, Brum (2005) faz quatro recomendações do que a empresa precisa ter para chegar ao objetivo final do endomarketing:

- Sintonia entre empresa e funcionários, incentivando contatos entre chefes e público interno; 
- Busca sempre de uma postura amigável, considerando sempre a contribuição de ambas as partes para o desenvolvimento da empresa;

- Trabalhar sempre com clareza, em processos de comunicação interna, cujo objetivo vá sempre direto ao ponto. A linguagem clara e a preocupação para deixar tudo correto são fundamentais para que a comunicação interna continue direta e objetiva;

- Compartilhar opiniões, possibilitando momentos em que todos possam optar e participar das decisões;

- Demonstrar o interesse e o pensamento sobre o assunto por meio do compartilhamento de ideias;

- Definir e planejar metas a serem seguidas, por meio das quais a empresa, por intermédio dos resultados planejados e organizados, consiga chegar ao resultado esperado, priorizando assuntos relevantes e tendo uma visão de toda a situação do interno e do externo da empresa.

Para a empresa ter seus objetivos alcançados com os planos de endomarketing, necessita seguir esses aspectos explanados por esses autores. Importa destacar que o sucesso a ser alcançado com a utilização das ferramentas de endomarketing é resultado de um processo contínuo e sem tempo para acabar. Por fim, além dos vários instrumentos, já citados anteriormente, um programa pode contar com o suporte de ações ou projetos relacionados ao marketing de incentivo e ao marketing cultural, expedientes já largamente utilizados pelas organizações, os quais contribuem e muito para o fortalecimento da relação com seus públicos internos e externos.

\section{PROCEDIMENTOS METODOLÓGICOS}

O presente estudo valeu-se de uma pesquisa descritiva, com abordagem qualitativa, por meio da observação, pesquisa de campo, aplicação de questionários e realização de entrevista, dados necessários para análise e compreensão do problema em questão. Essa modalidade de pesquisa é realizada por meio de fatos analisados, registrados e interpretados, sendo que o pesquisador não deve interferir em nenhum desses fatores.

Uma característica muito importante desse tipo de pesquisa é o modo como ela é realizada. $O$ pesquisador realiza a pesquisa descritiva por meio de 
questionários, da observação da organização e da coleta de dados. Quando a pesquisa descritiva assume uma forma mais simples, aproxima-se da pesquisa exploratória (ANDRADE, 2005).

Já em relação à abordagem, essa pesquisa caracteriza-se como qualitativa, a qual não se vale de análise estatística para a interpretação da realidade. Alguns aspectos dessa modalidade são apontados por Godoy (1995, p. 58):

[...] o processo é o foco principal de abordagem e não o resultado ou o produto; a análise dos dados foi realizada de forma intuitiva e indutivamente pelo pesquisador; não requereu o uso de técnicas e métodos estatísticos; e, por fim, teve como preocupação maior a interpretação de fenômenos e a atribuição de resultados.

Na pesquisa qualitativa não há enumeração, tampouco medição dos dados estudados e, da mesma forma, análise por meios estatísticos. Busca-se, portanto, o levantamento de dados descritivos, envolvendo pessoas ou lugares, por meio de processos interativos, tendo o pesquisador o papel do levantamento direto dos dados. Com as informações disponíveis, o pesquisador busca compreender as expectativas do público-alvo da pesquisa (GIL, 1999).

Quanto aos procedimentos, pelo fato de o trabalho abranger o problema de uma empresa do setor de aviamentos, optou-se pela realização de um "estudo de caso". Tal modalidade é uma estratégia metodológica que busca explorar o fenômeno dentro do contexto estudado e explora o problema em diferenciados ângulos. $O$ estudo de caso não requer apenas um modo para a coleta de dados, pode ser ou não realizado dentro da empresa ou organização (ROESCH; BECKER; MELLO, 1999).

Esta pesquisa contou, como unidade de análise, com o grupo Mercosul/Sul Catarinense Aviamentos, que atua no ramo da indústria têxtil há mais de 30 anos e está localizada na cidade de Criciúma, Santa Catarina. A Mercosul é a unidade da empresa responsável pela montagem de zíperes diferenciados e a Sul Catarinense é uma loja de atacado e varejo aberta ao consumidor.

Seus principais produtos são linhas para costura industrial e zíperes. Seu mercado, atualmente, fica na região sul de Santa Catarina, contando com alguns clientes no norte do estado e outros no Rio Grande do Sul. A empresa, atualmente, conta com 11 colaboradores, sendo que cinco trabalham na parte de montagem de zíperes (Mercosul), quatro atuam na loja de atacado e varejo (Sul Catarinense) e dois são vendedores externos. 
O plano de coleta de dados centrou-se na procura de informações na biblioteca, por meio de pesquisas em livros, catálogos e bibliografias, o que ajudou com relação aos dados para a elaboração e a construção do trabalho. A definição do instrumento usado para a coleta de dados se deu por meio do problema investigado pelo pesquisador (ANDRADE, 2005).

A abordagem qualitativa é apropriada para pesquisas que tratam melhor sobre a efetividade de um programa. Selecionar metas e construir alterações são características da abordagem qualitativa. Foram usados dois instrumentos nesta pesquisa, o estudo de caso e a pesquisa bibliográfica (ROESCH; BECKER; MELLO, 1999).

\section{RESULTADOS E DISCUSSÃO}

O presente estudo teve como objetivo avaliar o processo de endomarketing de uma empresa situada em Criciúma, Santa Catarina. Para o alcance de tal fim, foi realizada uma pesquisa com os funcionários e com o proprietário, procurandose estudar os procedimentos de endomarketing implantados na empresa e sua efetividade.

A primeira parte da pesquisa foi realizada com os funcionários, com o intuito de entender um pouco mais o público estudado e seus pensamentos, de acordo com o assunto. Por meio de categorias, foi dividido o questionário, conforme os objetivos específicos levantados. As categorias aplicadas são:

a) Categoria I: Fatos que identificam a pessoa que está sendo entrevistada;

b) Categoria II: Fatores que motivam e desmotivam o público interno a trabalhar na empresa;

c) Categoria III: Ferramentas usadas para comunicação interna da empresa;

d) Categoria IV: Sugestões que os entrevistados dariam para a melhoria do ambiente interno da empresa.

Logo após a aplicação do questionário junto aos funcionários, foi realizada uma entrevista com o dono da empresa. Esse trabalho de coleta de dados contou com o auxílio de um roteiro semiestruturado, sendo levantado o que o dono da empresa faz em seu ambiente organizacional para a motivação dos funcionários, sua compreensão quanto ao endomarketing e o que espera com o trabalho aplicado em sua empresa. 
A entrevista com o dono da empresa explorou os seguintes temas:

a) Missão da empresa;

b) Tempo de atuação;

c) Conhecimento sobre endomarketing;

d) Ferramentas para a motivação dos funcionários;

e) Metas a serem alcançadas.

Vale ressaltar que a entrevista feita com o dono da empresa foi gravada, a fim de contribuir para a parte escrita realizada pela pesquisadora, ajudando também na parte do entendimento da entrevista. O questionário foi realizado com todos os onze funcionários da empresa, que assinaram um termo de consentimento livre e esclarecido (TCLE). Cada um expressou seu pensamento e respondeu seu questionário de forma confidencial.

\section{APRESENTAÇÃO DOS RESULTADOS}

A Sul Catarinense foi fundada em 1986 por Adelino dos Santos. Após vinte e cinco anos de empresa, Adelino a vendeu para seu sobrinho, Gilberto dos Santos, que há seis anos a comanda. Gilberto fundou a Mercosul Aviamentos, uma extensão da Sul Catarinense. A parte da Sul Catarinense é uma loja de atacado para consumidores, e a da Mercosul Aviamentos é uma fábrica de zíperes diferenciados. A empresa atende o norte do estado de Santa Catarina e alguns clientes do Rio Grande do Sul.

A pesquisa é válida para a empresa, a fim de motivar seus funcionários, que estão sempre em contato com os clientes, lembrando que um funcionário motivado agrega mais para seu local de trabalho. A empresa, neste momento, busca crescimento na produção e investimento em um novo produto.

\section{Fatos que identificam o processo de endomarketing na empresa}

De acordo com o relato nos procedimentos metodológicos, os resultados obtidos no questionário aplicado na empresa são os seguintes. 
Quadro 1 - Categoria I, fatos que identificam a pessoa que está sendo entrevistada

\begin{tabular}{|l|l|l|l|l|l|}
\hline \multicolumn{2}{|l|}{ Cargo } & \multicolumn{2}{l|}{ Conhecimento sobre missão da empresa } & \multicolumn{2}{l|}{ Estabilidade no emprego } \\
\hline & $\mathbf{N}^{\mathbf{0}}$ & & $\mathbf{N}^{\mathbf{0}}$ & & $\mathbf{N}^{\mathbf{0}}$ \\
\hline Gerente & 1 & Sim & 7 & Sim & 10 \\
\hline Diretor & & Não & 4 & Não & 1 \\
\hline Supervisor & & & & & \\
\hline Encarregado & & & & & \\
\hline Técnico & & & & & \\
\hline Serviços gerais & 1 & & & & \\
\hline Administrativo & 2 & & & & \\
\hline Operacional & & & & & $\mathbf{1 1}$ \\
\hline Outros & 7 & & $\mathbf{1 1}$ & Total \\
\hline Total & $\mathbf{1 1}$ & Total & & & \\
\hline
\end{tabular}

Fonte: Elaborado pelos pesquisadores.

A partir dos dados levantados sobre o perfil dos pesquisados, pode-se verificar que pertencem a ambos os sexos, com idades entre 20 a 40 anos, a maioria. Observa-se, também, que a maioria dos entrevistados já está há mais de um ano na empresa, concluindo-se que não ocorreu muita rotatividade ao longo dos anos. Outro fato importante é que há quatro funcionários que não sabem qual é missão da empresa, um aspecto preocupante devido ao tempo que já estão trabalhando no estabelecimento. Por fim, também se conclui que apenas um funcionário não se sente com estabilidade na empresa.

Quadro 2 - Categoria II, fatores que motivam e desmotivam o público interno a trabalhar na empresa

\begin{tabular}{|c|c|c|c|c|c|c|c|}
\hline \multicolumn{2}{|c|}{ Recebe Feedback } & \multicolumn{2}{|c|}{$\begin{array}{l}\text { Transmite suas } \\
\text { opiniões, sugestões e } \\
\text { reclamações }\end{array}$} & \multicolumn{2}{|c|}{$\begin{array}{l}\text { Grau de satisfação } \\
\text { referente à empresa }\end{array}$} & \multicolumn{2}{|c|}{$\begin{array}{l}\text { Quais benefícios que a empresa } \\
\text { oferece aos funcionários }\end{array}$} \\
\hline & $\mathbf{N}^{\mathbf{0}}$ & & $\mathbf{N}^{\mathbf{o}}$ & & $\mathbf{N}^{\mathbf{o}}$ & & $\mathbf{N}^{\mathbf{o}}$ \\
\hline Às Vezes & 11 & Às Vezes & 4 & Muito satisfeito & 2 & Vale transporte & 6 \\
\hline Diariamente & & Sempre & 7 & Satisfeito & 9 & Comissão sobre vendas & 1 \\
\hline \multirow[t]{4}{*}{ Nunca } & & Nunca & & Insatisfeito & & Convênio odontológico, médico & \\
\hline & & & & & & $\begin{array}{l}\text { Convênio em farmácias, } \\
\text { supermercados, livrarias }\end{array}$ & 4 \\
\hline & & & & & & Cesta básica & \\
\hline & & & & & & Outros & \\
\hline Total & 11 & Total & 11 & Total & 11 & Total & 11 \\
\hline
\end{tabular}

Fonte: Elaborado pelos pesquisadores.

Com as respostas obtidas na categoria em questão, pode-se verificar alguns pontos que desmotivam e motivam os funcionários dentro do endomarketing 
implantado na empresa. Dentre eles está o feedback sobre a qualidade do trabalho solicitado pelo gestor da empresa aos seus funcionários, a vontade que os funcionários têm de transmitir suas opiniões e sugestões ao gestor, o grau de satisfação referente à empresa e, por último, os benefícios que a empresa oferece aos funcionários. Na primeira pergunta levantada sobre a questão do feedback por parte do gestor, todos os entrevistados responderam que às vezes recebem esse retorno referente à qualidade do seu trabalho. Já na segunda pergunta, que se refere à vontade de transmitir as suas opiniões e sugestões, ficou entre "às vezes" e "sempre", mas a maioria respondeu "às vezes".

Na penúltima pergunta, foi pontuado o grau de satisfação referente à empresa. A maioria respondeu que se sente satisfeita com a empresa, e apenas dois entrevistados alegaram um grau de satisfação maior, de muito satisfeitos. $\mathrm{Na}$ última questão levantada, foram questionados sobre quais os benefícios que a empresa oferece aos funcionários. A maioria levantou quatro dados: o vale transporte, a comissão sobre as vendas, as gratificações sobre as vendas alcançadas e o convênio em farmácias, supermercados e livraria. As organizações são formadas por pessoas motivadas, que por meio de seu trabalho e esforço ganham algumas recompensas. O feedback, por sua vez, é uma forma de contribuir para a motivação, dependendo da maneira como é realizado (BEE; BEE, 2002).

Existem dois tipos de feedbacks, sendo um em forma de crítica e o outro de elogio. Por meio desses pareceres é que os gerentes podem promover a motivação e o consequente sucesso de seus funcionários, até mesmo ajudando-os a identificar algumas dificuldades e a superá-las. O feedback positivo faz os colaboradores se sentirem lembrados e recompensados por seu trabalho realizado (BEE; $B E E, 2002)$. A comunicação entre o dono da empresa e seus funcionários é extremamente relevante, tanto para um feedback como para um diálogo entre ambos, dando aberturas para os funcionários transmitirem suas opiniões sobre o negócio. A partir da comunicação, o gestor consegue avaliar o grau de satisfação de seus subordinados e entender melhor os seus pensamentos (LUZ, 2003).

A satisfação do funcionário também resulta do clima organizacional da empresa. Por meio de projetos e informações levantadas, consegue-se perceber como está o andamento desse clima, que reflete no comportamento da empresa como um todo. Se os funcionários não estiverem satisfeitos, afetarão o clima da organização (LUZ, 2003).

Para conseguir a satisfação dos funcionários, são usadas algumas estratégias, como os convênios e as gratificações por atingirem os objetivos traçados, uma 
maneira de reconhecer o trabalho alcançado pelos colaboradores. Além de deixá-los satisfeitos, essas iniciativas acabam estimulando as vendas e a qualidade nos trabalhos que desenvolvem (BRUM, 2005).

Quadro 3 - Categoria III, ferramentas usadas para comunicação interna da empresa

\begin{tabular}{|l|l|l|l|l|l|}
\hline $\begin{array}{l}\text { Quais meios de } \\
\text { comunicação são usados } \\
\text { com os funcionários } \\
\text { (empresa } \\
\text { funcionário)? }\end{array}$ & $\begin{array}{l}\text { Quais meios de comunicação são } \\
\text { usados com a empresa (funcionário e } \\
\text { empresa)? }\end{array}$ & $\begin{array}{l}\text { Como você avalia a rapidez e clareza que } \\
\text { as informaçoses sobre a empresa chegam } \\
\text { aos profissionais? }\end{array}$ \\
\hline $\begin{array}{l}\text { Jornais internos, } \\
\text { murais }\end{array}$ & $\mathbf{N}^{\mathbf{0}}$ & & $\mathbf{N}^{\mathbf{0}}$ & & $\mathbf{N}^{\mathbf{0}}$ \\
\hline Internet, e-mail & 7 & Reuniões de equipe & 4 & Com rapidez & 4 \\
\hline Vídeos & & $\begin{array}{l}\text { Comunicação direta com o } \\
\text { supervisor ou diretor da empresa }\end{array}$ & & Atrasadas & 4 \\
\hline $\begin{array}{l}\text { Reuniões } \\
\text { periódicas }\end{array}$ & 4 & Outros & & Nunca chegam & 3 \\
\hline Manuais Técnicos & & & & & \\
\hline $\begin{array}{l}\text { Nenhuma das } \\
\text { alternativas }\end{array}$ & & & & & 11 \\
\hline Total & 11 & Total & 11 & Total & \\
\hline
\end{tabular}

Fonte: Elaborado pelos pesquisadores.

Na categoria que trata das ferramentas utilizadas na comunicação interna da empresa, foram levantadas três perguntas, todas questionando sobre a comunicação interna. Primeiramente, questionou-se quais são os meios de comunicação usados pela empresa em relação ao que precisa informar ao funcionário. Houve dois pontos mais destacados pelos colaboradores que foram internet e reuniões periódicas. Já na segunda pergunta foi feito o mesmo questionamento, mas de funcionário e empresa. Tivemos novamente como mais pontuadas as reuniões de equipe e caixa de sugestões. Por último, foi avaliada a rapidez e a clareza com que as informações chegam aos colaboradores. Nessa pergunta, obtivemos repostas variadas, como rapidez, lentidão e atrasos. A comunicação dentro da organização tem que ser clara e compreensível para todos os colaboradores.

Para facilitar a comunicação, o endomarketing levanta vários programas que podem contribuir para a melhoria do diálogo na empresa. Alguns instrumentos usados para esse contexto são ferramentas que vão simplificar e facilitar essas conversas. Manual e vídeo, manuais técnicos e educativos, revistas, jornal interno, revistas em quadrinhos, encarte da área escolhida, murais, cartazes motivacionais e reuniões são algumas formas que a empresa pode adotar para a melhoria da comunicação interna (BRUM, 2005). 
A comunicação interna é um fator que contribui para motivação dos funcionários. Assim, o entendimento com clareza do que a empresa quer transmitir para os funcionários e para os clientes é uma maneira de confortá-los e motivá-los (BRUM, 2005).

Categoria IV: Sugestões que os entrevistados dariam para a melhoria do ambiente interno da empresa

Na última categoria, foi levantada uma pergunta descritiva para saber as sugestões que os funcionários tinham quanto às melhorias no funcionamento interno da empresa, tanto na parte da comunicação com os funcionários como em relação às premiações e aos incentivos. Apenas cinco funcionários responderam essa pergunta. Três responderam que poderia melhorar a qualidade da comunicação do grupo, e dois responderam que a empresa poderia fazer um plano de saúde e ajudar no pagamento da gasolina como incentivo.

Para cada colaborador, existem diferentes necessidades. Cada um denomina desejos diferentes, que para serem suprimidos necessitam que a empresa conheça cada indivíduo dentro de sua organização. A empresa não precisa realizar cada desejo, mas sim motivar seus funcionários para alcançar suas metas (BERGAMINI, 1997).

A organização consegue entender melhor os indivíduos por meio de um estudo do comportamento motivacional humano, em que se estuda cada funcionário e sua felicidade pessoal. Um dos objetivos deste estudo foi entender melhor o que os funcionários pensam sobre a empresa e o que a empresa poderia oferecer para ajudá-los em seu cotidiano. Muitas vezes, com o auxílio desses estudos, as empresas ajudam os funcionários com vale alimentação, vale transporte, em custos com estudos e cursos, assim motivando e capacitando os funcionários a seguirem seus sonhos (BERGAMINI, 1997).

\section{Fatores de endomarketing na empresa, na visão da gerência}

A seguir, conforme o descrito nos aspectos metodológicos, são apresentadas as informações obtidas na entrevista realizada com o dono da empresa, dividida por temas. Nessa etapa, todas as perguntas foram descritas de forma direta, com a devida fundamentação teórica para dar sequência ao estudo.

Tema I: Missão da empresa 
Quanto à missão da empresa, o proprietário indicou alguns pontos que a compõem, como atender aos clientes com excelência, ter um produto de qualidade, um preço competitivo. Vindo de encontro a essa afirmação, alguns funcionários afirmaram ainda não saber a missão da empresa, algo que deveria ser passado logo de início, durante a contratação, levando-se em conta que quase todos os funcionários já estão há um tempo considerável na empresa, o que seria suficiente para que todos já soubessem qual é a sua missão.

Para atender os clientes com excelência, a empresa precisa buscar melhorias no seu ambiente interno, e os funcionários precisam estar motivados para atender e cumprir suas obrigações. Cliente e funcionários satisfeitos, mais lucro e crescimento para a organização (DAY; MONTINGELLI JÚNIOR, 2001).

Tema II: Tempo de atuação

Em relação ao tempo que a empresa existe no mercado, o entrevistado relatou que ela já atua há quase trinta anos, mas ele é seu proprietário apenas há seis anos.

O tempo de atuação conta muito em uma organização, visto que por meio dele podemos perceber se a empresa está consolidada em seu mercado. Empresas com mais tempo no mercado precisam buscar fortalecimento por meio de processos de inovação e do crescimento (DAY; MONTINGELLI JÚNIOR, 2001).

Quando ocorre a mudança de gestores na empresa, é necessário trabalhar o seu marketing interno. O novo gestor precisa mostrar sua capacidade, competência, coragem, criatividade e coração para os funcionários. Isso é uma forma de mostrar seus princípios (BRUM, 2005).

Tema III: Conhecimento sobre endomarketing

Quanto ao terceiro tema, foi perguntado ao dono da empresa se ele tem algum conhecimento sobre endomarketing. A resposta foi que ele possui esse conhecimento, ao qual teve acesso durante o curso de administração e em outros cursos realizados no decorrer da profissão de administrador, bem como pelas experiências práticas do dia a dia. $O$ endomarketing deve motivar as pessoas na organização, por meio de programas implantados. Com esses programas, os funcionários compartilham de uma mesma visão sobre o negócio da empresa, como os objetivos, metas e serviços. Um programa de endomarketing qualificado 
pode gerar novos funcionários com melhor postura dentro da empresa, novos conhecimentos, com vontade de aprender e crescer na organização (BRUM, 2005).

Tema IV: Ferramentas para a motivação dos funcionários

No quarto tema, foi discutida a questão das ferramentas usadas para motivação dos funcionários na organização. A primeira pergunta buscou saber quais ferramentas são utilizadas no endomarketing da empresa. Segundo o seu proprietário, é dada uma gratificação sobre as metas alcançadas, além disso, os uniformes, que são obrigatórios, são fornecidos gratuitamente pela empresa. Também é fornecida uma ajuda de custo para quem faz faculdade, pós-graduação ou cursos. Por fim, respondeu que são feitas reuniões semanais voltadas para alguns cargos da empresa.

Na segunda pergunta, ao ser questionado sobre como chegou a essas ferramentas, o gestor afirmou que foi por meio de uma consultoria realizada há alguns anos, com pesquisas feitas aos próprios colaboradores, e o desenvolvimento de ideias que ele mesmo teve e colocou em prática.

Na última pergunta, buscou-se saber se as ferramentas estão documentadas, obtendo uma resposta afirmativa e a explicação de que, quando foi desenvolvido o trabalho de consultoria na empresa, houve a elaboração de relatórios, os quais sugeriram a necessidade de ferramentas, que ainda não foi colocada em prática. Com a projeção de crescimento, a empresa pretende suprimir essa necessidade.

A comunicação interna existe em todas as empresas, mas vai de cada organização lapidar essa comunicação. Algumas informações podem ser passadas aos funcionários, por exemplo, por meio de um mural, para evitar conflitos e fofocas internas (BRUM, 2005).

O marketing de incentivo na empresa também é algo que conta muito com a ajuda de pessoas de fora da empresa, as quais trabalham com endomarketing, que é um conjunto de ferramentas e instrumentos que ajuda a vender uma mesma ideia ao público interno, cujo treinamento é sua maior ferramenta (BRUM, 2005).

A aplicação do plano de endomarketing na empresa precisa ser feita por uma equipe especializada, juntamente com os recursos humanos da empresa. O plano de endomarketing tem um tempo de duração um pouco mais longo, dependendo do objetivo que a empresa quer alcançar. No final do programa, é necessário deixar tudo registrado e documentado, especialmente em caso de problemas, e para a própria empresa continuar com o programa (BRUM, 2005). 
Tema V: Metas a serem alcançadas

Em relação às metas a serem alcançadas pela empresa, foram realizadas duas perguntas, finalizando-se, assim, a entrevista com o dono da empresa. A primeira pergunta levantada foi se ele pretende inovar na motivação dos funcionários, implantando algo que ainda não foi implantado. Sua resposta foi sim, pretende fazer algo mais específico devido ao fato de a empresa estar crescendo e de precisar de todos os colaboradores motivados e preparados para essa nova realidade.

Na última pergunta, e encerrando a entrevista, foi questionado qual é o resultado esperado com este estudo, cuja proposta está sendo implantada na empresa. O empresário alegou esperar algo que possa ajudar no crescimento interno da empresa, para que ela consiga novas ideias para motivar os colaboradores e melhorar a comunicação interna.

Diante disso, conclui-se que quando a empresa busca crescimento e inovações em seus processos, é preciso explicar aos funcionários o que está a acontecendo e se terão ganhos ou não com essas mudanças. Devido ao crescimento e às melhorias dentro da empresa, é aconselhável trabalhar técnicas e conceitos com o público interno para essa nova mudança e até mesmo para estarem preparados para o atendimento ao cliente (BRUM, 2005).

Algumas técnicas trabalhadas para esse crescimento são a difusão dos princípios da empresa, o reconhecimento do trabalho e do esforço de cada funcionário para conduzir as mudanças e, por último, o apoio psicológico para os funcionários que ainda se sentem inseguros com as mudanças (BRUM, 2005).

\section{Sugestões de Melhorias}

A partir da entrevista feita com o dono da empresa e do questionário voltado para os funcionários, alguns aspectos condizem com os conceitos de endomarketing, mas outros precisam ser verificados e tratados para a melhoria interna da organização.

A primeira questão analisada se deu quando conhecemos o perfil dos entrevistados e percebemos que quatro deles não sabem qual é a missão da empresa. Essa informação precisa ser passada a todos os funcionários já durante a sua contratação pela organização. Na entrevista, o dono da empresa relatou que a missão da empresa é atender os clientes com excelência, ter produto de qualidade e ter um preço competitivo, porém nem todos a conhecem. 
Ao analisar as questões respondidas pelos funcionários, o que se percebe é que o que pode ser melhorado é a comunicação interna da empresa. Muitos responderam que, internamente, a empresa faz uso de e-mail e que reuniões semanais com alguns funcionários também são realizadas. Isso condiz com o que o empresário respondeu. No entanto, ficou evidente um certo incômodo entre alguns colaboradores. Melhorias na comunicação, como o uso de um mural de informações, caixa de sugestões, reuniões quinzenais com todos da empresa para levantar problemas que ocorrem no dia a dia seriam ações simples de se realizar.

A maioria dos funcionários também respondeu que as informações chegam atrasadas ou com lentidão, comprovando que a comunicação interna deve ser reavaliada. Compreende-se que assim que a diretoria decidir colocar no mural algumas informações, o funcionário ficará melhor informado, evitando-se comentários distorcidos.

Quando se falou em motivação na empresa pesquisada e de ferramentas para acontecer essa motivação, seu proprietário apontou algumas ferramentas já utilizadas, como gratificação; ajuda no pagamento de cursos, faculdade e pós-graduação; uniformes gratuitos; e reuniões semanais com alguns funcionários. Estes responderam basicamente a mesma coisa, mas alguns pediram para também ter plano de saúde. De acordo com o empresário, essa sugestão já está sendo estudada e ele ainda pretende fazer novas melhorias devido ao fato de a empresa estar crescendo. Nesse ponto, a empresa, ao realizar reuniões, pode perceber quais são as necessidades de seus funcionários e estudar novas propostas para motivá-los.

Vale lembrar que para ocorrer alterações e melhorias na comunicação interna e motivação dos funcionários, a diretoria precisa estar empenhada nessas melhorias. A probabilidade de que os funcionários fiquem mais motivados com o desenvolvimento é considerável, trazendo um retorno satisfatório e produtivo, a fim de melhorar o desempenho da empresa, levando-se em conta a pretensão de crescimento.

\section{CONSIDERAÇÕES FINAIS}

Com o crescimento avançado e a modernização das organizações, manter-se no mercado tornou-se uma tarefa difícil. As empresas buscam investir em seu marketing e no seu crescimento para se tornarem referência no mercado, mas muitas vezes acabam se esquecendo de seus funcionários, que são o corpo da 
organização. Os funcionários precisam estar motivados para exercerem seu trabaIho com excelência e assim alcançar os objetivos da empresa.

O endomarketing é o marketing interno da empresa, que estuda seu público interno. Para motivar os funcionários, ele apresenta ferramentas e programas que desempenham essa função dentro da organização, conseguindo avaliar o grau de satisfação de seus funcionários. Os colaboradores são como os clientes da empresa, precisam ser bem tratados, assim a gestão necessita, também, sempre inovar na busca das ferramentas para a motivação.

O estudo teve como objetivo avaliar as ferramentas de endomarketing utilizadas em uma empresa de aviamentos situada em Criciúma, Santa Catarina. Por meio de entrevista com o dono da empresa, pôde-se identificar qual é o conhecimento de seu proprietário quanto ao endomarketing e quais ferramentas são utilizadas em sua empresa. Quanto aos colaboradores, foi aplicado um questionário com perguntas abertas para identificar o que os desmotivam e motivam, que ferramentas são utilizadas para a comunicação interna da empresa e, por último, colher sugestões de melhorias.

A partir do questionário, que foi respondido pelos 11 colaboradores que compõem o quadro da empresa, pôde-se perceber que há necessidade de melhorar a comunicação interna, tendo em vista que os funcionários alegaram que algumas informações chegam atrasadas ou chegam com lentidão, mostrando que esse tipo de comunicação está deixando a desejar.

A percepção dos colaboradores e do empresário quanto às ferramentas de endomarketing utilizadas na empresa seguiu a mesma linha de pensamento. Ambas as partes relataram os mesmos procedimentos adotados pela empresa, como reuniões semanais, gratificação sobre metas, ajuda de custo em cursos. Sobre a questão de motivação, o público interno apenas pediu um plano de saúde, que a empresa ainda não lhe proporciona.

Referente ao feedback dado pelo dono da empresa, todos se mostraram muito satisfeitos, alegando que o empresário dá o necessário retorno de como está o andamento do trabalho, gerando motivação ao funcionário para desempenhar seu papel na empresa.

É notório que para os funcionários trabalharem melhor e atingirem as metas, precisam se sentir queridos na organização. As pessoas precisam se sentir motivadas, pois sempre há os altos e baixos da vida. A motivação é fundamental para qualquer organização. 
Com o estudo apresentado, conclui-se que todos os objetivos específicos foram alcançados, tais como identificar as estratégias adotadas pela empresa, alinhadas ao conceito de endomarketing; detectar o grau de conhecimento do gestor acerca do endomarketing; avaliar a eficiência das iniciativas de endomarketing empreendidas pela gestão da empresa estudada; e, por fim, apresentar sugestões à empresa objeto deste estudo a partir dos resultados obtidos na pesquisa.

Outros estudos que podem ser realizados futuramente são sobre os programas de endomarketing que se adequam às metas de crescimento da empresa, como os de treinamento de futuros colaboradores e ou aqueles referentes a fatores externos que ajudam na motivação do seu público interno.

\section{REFERÊNCIAS}

ALLEN, J. G. Pirâmide de Maslow: la jerarquía de las necesidades humanas. [S.I.: s.n., s.d.]. Disponível em: <https://psicologiaymente.net/psicologia/piramide-demaslow>. Acesso em: 12 abr. 2016.

ANDRADE, M. M. Introdução à metodologia do trabalho científico. 7. ed. São Paulo: Atlas, 2005. $174 \mathrm{p}$.

BEE, R.; BEE, F. Feedback. São Paulo: Nobel, 2002. 62 p.

BEKIN, S. Conversando sobre endomarketing. São Paulo: Makron Books, 1995. $149 \mathrm{p}$.

BEKIN, S. Endomarketing: como praticá-lo com sucesso. São Paulo: Pearson Prentice Hall, 2005. 186 p.

BERGAMINI, C. W. Motivação nas organizações. 4. ed. São Paulo: Atlas, 1997. $214 \mathrm{p}$.

BRUM, A. M. Endomarketing como estratégia de gestão: encante seu cliente interno. 3. ed. Porto Alegre: L\&PM, 2005. 178 p.

CERQUEIRA, W. Endomarketing: educação e cultura para a qualidade. Rio de Janeiro: Qualitymark, 1999. $161 \mathrm{p}$.

DAY, G. S.; MONTINGELLI JÚNIOR, N. A empresa orientada para o mercado: compreender, atrair e manter clientes valiosos. Porto Alegre: Bookman, 2001. $265 \mathrm{p}$. 
GIL, C. A. Métodos e técnicas de pesquisa social. São Paulo: Atlas, 1999.

GODOY, A. C. Introdução à pesquisa qualitativa e suas possibilidades. Revista de Administração de Empresas, v. 35, n. 2, p. 57-63, 1995. [on-line]. Disponível em: <http://dx.doi.org/10.1590/S0034-75901995000200008.>. Acesso em: 25 maio 2016.

INKOTTE, A. L. Endomarketing: elementos para a construção de um marco teórico. 2000. 144 f. Dissertação (Mestrado em Engenharia de Produção) - Universidade Federal de Santa Catarina, Florianópolis, 2000. Disponível em: <http:// endomarketing.com/wp-content/uploads/2014/10/publicacao-tese-alexandreluz-inkotte.pdf.>. Acesso em: 24 nov. 2015.

KOTLER, P. Administração de marketing: análise, planejamento e controle. São Paulo: Atlas, 1981. $361 \mathrm{p}$.

KOTLER, P. Administração de marketing. 10. ed. São Paulo: Prentice Hall, 2000. $764 \mathrm{p}$.

KOTLER, P.; ARMSTRONG, G. Introdução ao marketing. 4. ed. Rio de Janeiro: LTC, 2000. 371 p.

LOEN, R. O. Administração eficaz. 3. ed. Rio de Janeiro: J. Zahar, 1976. 338 p.

LUZ, R. Gestão do clima organizacional. Rio de Janeiro: Qualitymark, 2003. 143 p.

MASLOW, A. H. Maslow no gerenciamento. Rio de Janeiro: Qualitymark, 2001. $361 \mathrm{p}$.

MINADEO, R. Gestão de marketing: fundamentos e aplicações. São Paulo: Atlas, 2008. $464 \mathrm{p}$.

ROESCH, S. M. A.; BECKER, G. V.; MELLO, M. I. Projetos de estágio do curso de administração: guia para pesquisas, projetos, estágios e trabalho de conclusão de curso. 20. ed. São Paulo: Atlas, 1999. 301 p.

URDAN, F. T.; URDAN, A. T. Gestão do composto de marketing: visão integrada de produto, preço, distribuição e comunicação, estratégias para empresas brasileiras, casos e aplicações. São Paulo: Atlas, 2006. 340 p. 